\title{
Celebración del Tricentenario del Discurso del Método de Descartes. Homenaje de la Universidad de El Salvador, 1937. (Primera parte)
}

\author{
Otto Mejía Burgos \\ Universidad Don Bosco
}

Resumen: En el presente artículo se trata de hacer una aproximación a las primeras seis conferencias cartesianas desarrolladas por distintos intelectuales en el recinto de la Universidad de El Salvador, las cuales tuvieron lugar del 13 de septiembre al 18 de octubre de 1937. La rectoría, para el éxito de las mismas, hizo invitación a reconocidos intelectuales, académicos, literatos y periodistas, sin distinción de credos o de escuelas de pensamiento a fin de explorar la obra del Ilamado "Padre de la Modernidad" en sus distintas facetas: filosófica, científica y cultural. En ese momento se tenía la idea de que el estudio de la filosofía era necesario tanto para la consolidación de una democracia en formación como para el mejoramiento intelectual y moral del pueblo. Se debe aclarar que muchos de los puntos tratados en las conferencias, en ocasiones, son armónicos $y$, en ocasiones, se vuelven contradictorios producto de los diferentes matices con los que fueron tratados por los participantes.

Abstract: This article makes an approximation to first six discourses about Descartes, pronounced bye different intellectuals in the University of El Salvador, developed since September 13 to October 18 from 1937. The rectory, for the success of the same, makes an invitation to intellectuals, academics, man of letters and journalists, who participated without pay attention about their beliefs or schools. The objective was to introduce the different work's faces of the "Father of the Modernity": philosophical, scientific and cultural. In that moment was the idea that philosophy was very important to build an early democracy as to get better the culture and the ethic of the country. Is important to advice sometimes, the arguments getting conflictive between then and sometimes are harmonics as result of the different points of view of the participating.

\section{Palabras claves}

Historia intelectual, pensamiento político, filosofía, René Descartes, Universidad de El Salvador, El Salvador, siglo veinte.

\section{Keywords}

Intellectual History, Political Thought, Philosophy, René Descartes, Universidad de El Salvador, El Salvador, Twentieth Century 


\section{Introducción}

Después de los fatídicos eventos de 1932 parecería que el panorama para El Salvador era obscuro. Con una economía agobiada y con un clima de duelo aún latente no se percibía ningún espacio de donde pudiera surgir alguna forma de expresión cultural. Es así como de manera insospechada surgió un nuevo grupo de intelectuales que empezaría a abrir la ruta. Dicha intelectualidad establecería el indigenismo como línea a seguir tanto en literatura, como en pintura, música y arqueología, pero también intentaría llevar a cabo una política de la cultura más amplia en donde la Universidad de El Salvador jugaría un papel muy importante.

Debido a la insurrección, la Universidad fue intervenida por el gobierno. Lara-Martínez (2011) sostiene que ese mismo año, universitarios e intelectuales se encargarían de rendirle tributo, en ocasión de su primer centenario luctuoso al poeta alemán Wolfgang Von Goethe (p. 99). Las conferencias que se desarrollaron fueron dirigidas por Jacinto R. Paredes, Sarbelio Navarrete, Adolfo Pérez Menéndez y Salarrué. Desde esta óptica el editorialista Félix Antonio Hernández escribió en el diario El Día lo siguiente: "afirma el eminente maestro de la juventud francesa, Jules Payot, que en El Ejército y en la Universidad, deben estar los mejores elementos humanos con que cuente una nación, su máxima y óptima razón ser" (Hernández, 1932, p. 2).

Hasta ese momento se consideraba que la educación que se había impartido en el Alma Mater había sido deficiente y con planes de estudio inadecuados (Hernández, 1932 , p. 2). Por otra parte, la Universidad debía de jugar un papel de orientadora de la juventud salvadoreña y de la ciudadanía en general ya que de lo contrario estas podían caer en el desorden y la anarquía. Se consideraba que para la sociedad era peligrosa una juventud mal encauzada, por lo que se le debía de inyectar ideales sanos, sublimes y renegadores, los cuales contrarrestarían las bajas pasiones, "el odio ciego, la envidia, y la intriga", que solo fracturaban a la sociedad (Reformas Universitarias V, 1932, p. 4). Estos antivalores evidentemente eran atribuidos al materialismo por lo que se debían de sembrar los sentimientos espiritualistas:

Nuestra enseñanza, lo repetimos, ha sido y es demasiado materializada. Y los resultados los tenemos a la vista. La juventud se ha encontrado desorientada, y por ello no sabe lo que quiere, como lo afirma el maestro Vasconcelos. 
El movimiento comunista que ha afligido tanto a la Patria en estos días, ha llegado a constituir un caos en el que se han precipitado aquellos desgraciados desposeídos de ideales sanos; pero dueños de un acervo hereditario de sentimientos materializados que, a pesar de todo, denuncia un sufrimiento de la humanidad (...) El mismo maestro (Dr. Juan Artiga) nos agrega lo siguiente: "Al colaborar en esta gran crisis que la humanidad sufre, como un episodio de su desenvolvimiento y una prueba de purificación, los espiritualistas deben asumir grandes responsabilidades, y deberes más severos que el resto de sus conciudadanos". (Reformas Universitarias V, 1932, p. 4)

Bajo esta dirección, para septiembre de 1937, bajo la rectoría de Sarbelio Navarrete, la Universidad de El Salvador, organizó un ciclo de conferencias cartesianas en honor al aniversario de los 300 años de publicación del Discurso del Método (Llerena, 1937, pp. 1-2)1. Al destacado evento cultural se dieron cita el Presidente de la República, Maximiliano Hernández Martínez, Ministros de Gobierno, Magistrados, Diputados de la Asamblea Legislativa, Gobernadores Departamentales, Catedráticos Universitarios, estudiantes y público en general (Navarrete, 1937, p. 1). Es interesante observar que con el objeto de brindar su apoyo oficial al acontecimiento, Martínez ocupó el paraninfo para hablar por unos breves minutos sobre el hermetismo y filosofía oriental.
La participación del Jefe de Estado -aunque en disonancia con el tema a abordar- fue interpretada por el diario oficial de la época como una muestra de la gran estima que este sentía por las manifestaciones de cultura en sus diferentes aspectos (Como juzga la prensa, 1937, p. 4). Según la visión oficial, este era un claro ejemplo de cómo los hombres de gobierno debían de interesarse por las actividades educativas. Es más, Ana Rosa Ochoa, intelectual y colaboradora de la revista Cipactly, propuso que todas las sucesivas conferencias cartesianas fueran transmitidas por la radiodifusora nacional, tal y como lo fueron las de apertura, o sea, las del Presidente Martínez y la del jurisconsulto Navarrete (Ochoa, 1937, p. 5).

\section{Bajo el signo de Descartes}

La disertación de inauguración estuvo a cargo del rector Navarrete y fue titulada "Bajo el signo de
Descartes" (Bajo el signo, 1937, p. 2). En esta, la máxima autoridad universitaria, sostuvo que Descartes 
había sido el responsable de dar muerte a la filosofía de la Edad Media, la cual, según él, había sido una mezcla de aristotelismo y teología. Para Navarrete, Descartes vino a romper con un periodo histórico donde la filosofía se encontraba supeditada a los dogmas inexpugnables de la Iglesia Católica y a las sutilezas de la metafísica. La gran hazaña de Descartes fue, entonces, que en medio de un ambiente escolástico asfixiante, reivindicó la duda metódica y la razón y de ahí que en un sentido amplio sea considerado como el fundador de la civilización moderna.

Ahora bien, si la filosofía había sido esclava de la religión en el Medioevo, no debía permitirse que se convirtiera en una nueva esclava de la ciencia en la época moderna (Navarrete, 1937, pp. 11-12). Tal aseveración iba en el sentido de que, en el esquema positivista, la filosofía es reducida a una simple epistemología o teoría de las ciencias, pero más bien Navarrete consideraba que ésta debía gozar de un carácter autónomo y que además debía estar fundamentada en la ciencia, tal y como Descartes lo propuso en el siglo XVII a través del análisis de la lógica matemática y del estudio de los fenómenos naturales. Este método, por decirlo de alguna manera, sería una forma más exacta de aproximarse a la verdad.

Aquí Descartes estaría proponiendo una doble vía metódica, primero la de la razón conceptual y segundo la de la razón experimental. La primera para descubrir los asuntos del mundo subjetivo de la conciencia y la segunda para descubrir el mundo objetivo de la realidad exterior, con lo cual, de paso, estaría zanjando la infinita lucha entre idealistas y empiristas. Esto definitivamente constituiría una revolución, ya que implicaba el descubrimiento de la "verdad" mediante la libre investigación en donde el sujeto cognoscente tendría la oportunidad de probar o reprobar su verdad, sin imposiciones arbitrarias y $\sin$ autoridades preestablecidas. Es así como desde un punto de vista formal quedaría instalada la antinomia entre racionalismo cristiano con Santo Tomás de Aquino como máxima expresión y el racionalismo laico como corriente renovadora del Renacimiento.

Desde un punto de vista político, Navarrete (1937) expresó que fue mediante el pensamiento cartesiano que tuvo lugar el surgimiento de la democracia, tal y como se conoce hoy en día (p. 1). La Revolución Francesa2 sería el suceso determinante para romper de forma definitiva con la tiranía monárquica en base a la proclama de sus tres grandes principios universales: libertad, igualdad y fraternidad. En base a los conceptos de Navarrete, Francisco Morán, profesor de primaria y antiguo miembro del partido vitalista, sostenía que la democracia republicana era el 
único sistema que podía prevalecer frente el absolutismo, la encomienda colonial, la monarquía y la intolerancia de las ideas:

En América, dentro de los principios democráticos fueron concebidas las cartas magnas, redactadas las leyes menores y organizadas las instituciones. La heráldica republicana inspiró escudos y banderas. Los acordes de la Marsellesa repercuten en cada himno nacional de las repúblicas americanas. $(1937$, p. 8)

\section{Sobre la formación de nuestra propia cultura, a la luz de Descartes}

Este fue el tema de la ponencia de Sofonías Salvatierra3, quien manifestó -que a su parecer- la "duda metódica" planteada por Descartes no era nada más que la invitación a suprimir los prejuicios intelectuales que tendían a contaminar la verdad, la cual, más bien tenía que estar dirigida por la evidencia (Salvatierra, 1937, 39-40). En este sentido, el ego cogito ergo sum no sería otra cosa que una evidencia intuitiva que probaría, primero la capacidad contemplativa del ser y segundo la existencia biológica de ese ser a partir de esa capacidad contemplativa.

A continuación, Salvatierra establecería que Grecia fue el origen de la cultura europea, que, como un reflejo del espíritu humano, creó la filosofía. Desde ese entonces, el hombre se vería impulsado a conocer lo que era la verdad. A partir de ahí, para Salvatierra (1937) se iniciarían las grandes rutas de la religión y de la filosofía por encontrar la verdad. Este proceso sería precisamente el que conduciría al establecimiento de las diversas religiones positivas y a la fundación de un sinnúmero de escuelas filosóficas hasta llegar a Descartes quien sería el responsable de provocar la transición del mundo antiguo al mundo moderno. Efectivamente, Descartes viviría en los tiempos donde los filósofos fueron sustituidos por los Padres de la Iglesia que se encontraban profundamente influenciados, primero, por el idealismo platónico y después, por el realismo aristotélico que fueron entremezclados con el judaísmo y el cristianismo. En este esquema, toda verdad que no fuera obtenida mediante la revelación divina era declarada "herética" (pp. 42-44).

La premisa lanzada por el sistema cartesiano era que la razón no se podía desenvolver sin libertad. Es debido a esto que para el filósofo francés, bajo ningún pretexto, se podía limitar el ejercicio de la razón, condición indispensable para superar el 
oscurantismo. En este sentido, es justo decir que el pecado original de la Edad Media aún permanece en la actualidad y es el de querer presentar al hombre verdades tasadas cuando la verdad debe ser conquistada por cada quien tanto como un derecho como un deber. La revolución cartesiana consiste, entonces, en quebrantar todas aqueIlas formas de verdad oficial anquilosadas. Según Salvatierra (1937), en el caso de América, el problema había consistido, precisamente, en copiar todas estas verdades provenidas de Europa (pp. 45-60).

Retomando a Descartes, Salvatierra sostenía que América no debía alimentarse de opiniones ajenas, sino usar su propio juicio para encontrar otras verdades mejores y distintas. América debía conocerse a sí misma para crear una filosofía original en base a su propia geografía, tradición, mentalidad y modo psicológico. Esta era la única forma mediante la cual el mensaje de América sería vario, distinto y complementario al pensamiento universal. Salvatierra creía que no es que el pensamiento europeo fuera superior al americano es que, simplemente, debía ser distinto por estar fundamentado en derroteros distintos. Hasta ese momento, América se había nutrido de verdades extrañas, las cuales -no es que fueran malas-, pero debían ser utilizadas solo de forma auxiliar para entender las verdades americanas, ya que lo importante era elaborar una personalidad creadora. En el caso particular de Centroamérica parecería que el aporte original debía ser el regionalismo expresado en unidad histórica, geográfica, política y espiritual:

En donde quiera que se piense, en cualquiera de sus regiones, es el mismo pensamiento centroamericano y emerge uniforme de todo el agregado (...) somos geográficamente como un enlace de manos continentales, será forzoso que seamos una conjunción de expresiones en la literatura, en la filosofía, en la ciencia y en el arte. Para eso es indispensable que seamos una sola expresión política. (Salvatierra, 1937, pp. 63-64).

\section{Descartes ante la razón y la fe}

Esta disertación fue llevada a cabo por un miembro de la Iglesia Católica al cual solo se le identificaría como el hermano marista Heriberto. En realidad, este autor vendría a contrastar y a matizar las dos anteriores (Heriberto, 1937, pp. 67-68). Para comenzar sostendría que el problema fundamental de toda la filosofía cartesiana era responder a la pregunta sobre si era posible conocer la verdad con 
certeza o si por el contrario, se estaba totalmente condenado a la duda eterna. La respuesta era alentadora ya que, según el conferencista, el entendimiento humano solo utilizaba la duda a manera de método y de ahí que a partir de ego cogito ergo sum Descartes Ilegara a la conclusión de que "negar el yo pensante era rechazar lo que el pensamiento supone".

Por otro lado, la crítica tradicional que la filosofía le ha hecho a Descartes es que éste nunca pudo desprenderse totalmente del dogmatismo que combatió, circunstancia que desde el punto de vista de la fe sería una virtud en el sentido de que todo el racionalismo cartesiano encontraría su fundamento último en un Dios real. Lo que sucede es que se considera que Descartes encontró un punto intermedio entre el dogmatismo a priori exagerado y el escepticismo pesimista desesperante (Heriberto, 1937, pp. 69-72). Según el ponente, el error de la escolástica fue dejarse corroer por la rutina, lo cual la llevó a su propia destrucción. En ese sentido, si bien es cierto Descartes propugnaría por una razón inconforme, el fundamento de su filosofía sería teológico.

Descartes vio en la actividad mental el obrar que seguía al ser, es decir, no era posible que el filósofo que pensaba no existiera. Ahora bien, el hombre, en su proceso de descubrir la verdad podía ser engañado por sus sentidos, pero nunca podía ser engañado por Dios, porque este era infinitamente bueno, lo cual haría caer al sistema cartesiano en un espiritualismo idealista y por tanto, las verdades de la Iglesia no podían estar sujetas a la duda prudencial. La diferencia entre la duda de los escépticos y la duda cartesiana, era que la primera era una duda por dudar y la segunda era un medio provisional para llegar a la verdad, pero la cuestión es que nunca ha habido un pirrónico perfecto ya que como dudan de todo, también tendrían que dudar de su propia duda (Heriberto, 1937, pp. 72-77).

Descartes, en definitiva, demostraría la existencia de Dios por medio de la introducción de su categoría de la substancia infinita. En este sentido, la idea de la infinitud solo podía venir de un ser infinito, un Dios infinitamente bueno y sabio que no podía haber creado al hombre por error. De este modo, todas las posibles verdades encontradas por Descartes partirían de una verdad universal y necesaria. Evidentemente, esta peroración fue una legitimación y defensa de los dogmas de la Iglesia Católica, ya que Heriberto (1937) sostenía que Descartes al fraguar su teoría respetó la invulnerabilidad de Dios y del catolicismo, a pesar de haber forjado junto a Bacon, el método inductivo y experimental de las ciencias o, en otras palabras, la verdades de la fe quedarían excluidas de la duda metódica cartesiana, por saberlas este, incontrovertibles (pp. 76-82). 


\section{Del origen y de la perennidad de la filosofía}

El profesor de escuela primaria, filósofo y escritor Saúl Flores fue quien dictó la tercera conferencia; la misma no se centra en el pensamiento de Descartes propiamente como tal, sino que más bien es un pequeño esbozo del desarrollo de la filosofía a través de la historia (Flores, 1937, 89-96).

Flores, hizo notar que entre los conferencistas que lo precedieron existía una discrepancia saludable, que era propicia al quehacer filosófico. Esto se explicaba por el hecho de que la crítica había sido la gran impulsora del progreso teórico a través de la historia. Ahora bien, el otro gran motor que había movido a la filosofía desde sus orígenes era el reconocimiento de la propia ignorancia; en tal sentido aquel que se considerara tener la verdad absoluta era inepto para el ejercicio intelectual. En realidad, para Flores el hombre había empezado a filosofar desde el primer instante en que deseó conocer y por tanto, domar el medio, el universo y su destino.

Desde un punto de vista biológico, Flores (1937) sostenía que el pensamiento surgió a través de la liberación de las manos, que fue, precisamente, el instante en que se creó la técnica a través de la construcción de distintas herramientas de trabajo. Al utilizar sus manos el hombre se hizo más hábil, complejizando así sus actividades cotidianas y por tanto, incrementando el tamaño de su cerebro. Otro factor crucial en este sentido fue la conquista del fuego, ya que la cocción de los alimentos hizo innecesarios los músculos poderosos del rostro y de la mandíbula que más bien se encaminarían al desarrollo del lenguaje que, en proceso inverso a la manipulación física de objetos, vigorizarían la masa cerebral. Debido a esto es que Henry Berr diría: "La mano y el lenguaje he ahí la humanidad" (pp. 94-95).

Por otro lado, Flores creía que la filosofía surgió a partir del mito, en un instinto del hombre por dominar las fuerzas de la naturaleza a las cuales dotó de un carácter divino, luego sintió la necesidad de explicarse racionalmente los fenómenos y se empezaron a desarrollar las distintas escuelas de pensamiento. Posteriormente, a partir de sus distintas necesidades concretas, crearía las ciencias particulares, que eran pequeñas visiones de un panorama general que solo podía ser dado por la filosofía y, de hecho, la ciencia encontraría sus primeros postulados en los filósofos antiguos. En ese sentido, Grecia sería la madre de la mayor parte de las diferentes visiones filosóficas y pre-científicas desde la Escuela Miseliana, pasando por los pitagóricos, los eleatas, la escuela de Abdera, los sofistas, los sistemas de Sócrates, Platón y Aristóteles, los 
estoicos, los epicúreos, los cínicos y los sistemas neoplatónicos como el de Plotino con los que se cerraría la Antigüedad (pp. 99-102).

A continuación se da paso a la Edad Media, que ya se ha explicado que se empezaría a desquebrajar a partir de los descubrimientos de Copérnico, Kepler y Galileo Galilei. En realidad, Descartes sería como la conclusión de todo este movimiento de ilustración que predominaría durante todo el siglo XVII. Ahora bien, pensadores del siglo XIX como Unamuno harían serías críticas al cartesianismo sosteniendo que el verdadero principio era Sum, ergo cógito: "soy luego pienso", lo cual quiere decir que el pensamiento es atributo de la existencia y no a la inversa. Por otra parte, Descartes sería infiel a su propio método cuando toma sugestiones de su imaginación para sustentar su sistema: "Después de haber comenzado a dudar de todo, acabó por creerlo todo". Ahora bien, la importancia del cartesianismo radicaría en abrir un nuevo sendero a sus continuadores.

Flores terminó aseverando que los sistemas filosóficos que predominaron en el siglo $X X$ fueron el intuicionismo de Bergson, el pragmatismo de William James, la fenomenología de Edmund Husserl y el meliorismo de Lester F. Ward. Curiosamente no mencionó el marxismo. Dentro de la filosofía americana destacaba, según él, la obra de José Ingenieros. En conclusión, para Flores la filosofía nunca moriría ya que, parafraseando a Höfding, la filosofía trataba cuatro grandes problemas imperecederos: el lógico, el cosmológico, el ético y el psicológico, los cuales siempre tratarían de ser resueltos independientemente de la modalidad de la escuela: materialista, espiritualista, idealista, empirista, racionalista, criticista, etc., o, en otras palabras, el hombre está condenado a filosofar (pp. 113-117).

\section{La obra matemática de Renato Descartes}

Efraín Jovel fue quien desarrolló la cuarta conferencia (1937), aparentemente era un estudiante muy versado en la física y la matemática de la época. En primer lugar habría que decir que desde los orígenes del pensamiento hubo filósofos que trataron de encontrar un respaldo físico a sus especulaciones, entre ellos se encontraban los griegos, quienes ya se preocupaban por las magnitudes de las cosas concretas y daban las soluciones en forma de construcciones geométricas. Luego Leonardo de Pisa en el Siglo XII, enseñaría en Europa los rudimentos del álgebra hasta las ecuaciones de segundo grado mediante la determinación de las incógnitas por considerarlas geométricas. Sin detrimento de esto habría que decir que el antecesor 
directo de Descartes fue Vieta, en el Siglo XVI.

Descartes revolucionó la matemática y la consideró el mejor método para afirmar su criterio. Según Jovel (1937), Descartes unió el álgebra y la geometría e interpretó a esta por aquella descubriendo los símbolos y las figuras. En el campo de la aritmética a Descartes le interesaron los números perfectos; se puede decir que si Diofanto señaló las bases del álgebra y Vieta ensanchó el horizonte, Descartes llegó a sus profundidades. Por otra parte, Descartes fue el creador del algoritmo exponencial que simplificó notablemente las expresiones y también fue el primero en tratar las funciones algebraicas; en geometría se valió de las coordenadas que llevan su nombre para determinar la posición de un punto en un plano (pp. 122 -123).

Históricamente se ha considerado que los filósofos han estado peleados con los números, pero Descartes sería uno de los pocos filósofos en combinar ambas facetas, de hecho, es el padre de la geometría analítica la cual permite hacer a un lado las figuras geométricas para quedarse solamente con su traducción algebraica en ecuaciones del mismo grado, esto es lo que se conocería como la teoría de la cantidad, es decir, Descartes se elevaría de la geometría al álgebra. Por otro lado, la geometría de Descartes es una cinemática, ya que pretende excluir la dinámica. Se cree que Descartes también tuvo la gloria de compartir con Galileo el enunciado del principio de inercia. En Dióptrica, descubrió y enunció la ley de refracción de la luz, en definitiva, Descartes sería el continuador de la obra geométrica de los griegos y un metafísico medieval al mismo tiempo, debido a esto la mayor crítica que se le hace es que desconoció que el único basamento de la física es la experiencia y que la matemática debe fundirse con la física, o sea, con la realidad y no con la idea. Finalmente otro de los grandes atributos de Descartes fue ser el precursor de la escuela positivista (Jovel, 1937, pp. 126-132).

\section{La teoría cartesiana de las verdades eternas}

Esta sería la última de las primeras seis conferencias del ciclo cartesiano. Estuvo a cargo de Rafael F. Claros quien, en realidad, hizo una crítica a dicha teoría como un método para encontrar la verdad, tal como lo había establecido el propio Descartes (Claros, 1937, pp. 137-138). Ahora bien, que Descartes se hubiese equivocado en alguno o en muchos de sus postulados no reducía su grandeza. En primer lugar ¿Cuáles son esas verdades eternas? Son los axiomas de la metafísica y de la matemática, como por ejemplo "la 
gratitud es buena", "la blasfemia es mala", "2+2 es igual a 4". La tesis fundamental de Descartes es que estas verdades son establecidas y determinadas por Dios y, por tanto, dependen enteramente de Él.

El dogma cartesiano consiste en que estas verdades serían establecidas en la naturaleza por el decreto de la voluntad de una potencia infinita, la cual se vería encarnada en Dios, que es lo que se conocería vulgarmente como el "voluntarismo cartesiano", pero el ponente consideraba que en dicha teoría había vacilaciones o más bien inconsistencias. ¿Por qué? Porque el ser de las cosas no es potencialmente infinito como lo es Dios, la potencialidad imbíbita de aquellos seres que no son Dios, está bien delimitada en sus potencialidades, es decir, la potencialidad de un ser no es algo vago o indefinido de tal modo que una semilla de aguacate pueda llegar a convertirse en un mango o viceversa, lo que Claros (1937) concluye es que no es que Dios no pueda hacer de una semilla de aguate un mango, sino que la semilla de aguacate es incapaz por sí misma de llegar a ser mango (acto imposible) y completamente ajeno a la potencia divina (pp. 141-144).

De esta misma manera, no podía admitirse que las verdades eternas derivaran de la voluntad divina, estas elucubraciones serían, precisamente, los resabios de la filosofía medieval en Descartes. Teológica y anticientíficamente hablando Dios solo sería como un "regulador" de esa potencialidad fruto de su voluntad, pero la verdad es que esta potencialidad se encontraría en la esencia misma de las cosas. Puede verse como hay en Descartes una determinación por querer conciliar la metafísica aristotélica con el credo cristiano, que es precisamente lo que se quería romper en ese momento (Claros, 1937, p. 145). Ahora bien, las leyes de la física no han sido de modo alguno imperecederas, incluso, podría decirse que no existe una física sino múltiples físicas, que en consecuencia nos darían una gama de mundos posibles que podrían coexistir paralelamente. Estos mundos posibles "en acto" no serían el fruto de una voluntad divina, sino más bien, serían ajenos e independientes a ella.

En este contexto, la verdad entendida como la adecuación entre el ser y la inteligencia empezaría a fisurarse para dar paso a una gama de verdades relativas tal como lo propondría más tarde la teoría de la relatividad especial de Einstein, consecuencia del principio de relatividad de Galileo, con los cuales se eliminaría por ejemplo, la posibilidad de la existencia de un espacio y un tiempo absolutos en el conjunto del universo (Claros, 1937, p. 147). Evidentemente estos conceptos fueron desarrollados con posterioridad a Descartes, pero lo 
que es un hecho es que Descartes se quedó deambulando todavía en las concepciones metafísicas artificiales como las de una causa única eficiente. Causa que en términos teológicos se traduciría en la idea de Dios y que hasta cierto punto responde a una concepción antropomorfa de la realidad, o lo que modernamente es entendido como un gran arquitecto, que surge a partir de la negación del dogma a que haya surgido algo de la nada.

Ahora bien, cuando Descartes intenta establecer los cimientos mismos de la verdad, lo hace en lo que hay más oscuro de la arbitrariedad: la fe. Por tanto, su sistema entraría en clara e ingenua contradicción desde la raíz. Esta concepción quedaría muy lejos del positivismo de Stuart Mill y de Herbet Spencer quienes para encontrar la verdad se fundamentarían en la experimentación pura4 y de ahí que se diera pie al empirismo, el cual establece que el conocimiento científico es meramente probable y no necesario como aseveraba Hume y otros antecesores. En todo caso, Mill rechaza todo tipo de concepto a priori como la idea de Dios, la cual no está sujeta a experimentación. En definitiva, el error del sistema cartesiano sería colocar la voluntad, precedida por el entendimiento divino, como principio supremo de todas las demás esencias, principio que ya se encontraba en la Suma Teológica ( $1^{\text {a }}$ parte, q. 15; art. 2). (Claros, 1937, pp. 151-153).

\section{Conclusión}

A pesar de las distintas divergencias entre los ponentes, se puede llegar a ciertas conclusiones indiscutibles como que Descartes es el padre de la filosofía moderna y que fue uno de los máximos propiciadores de la revolución científica de su tiempo a pesar de los ribetes teológicos, platónicos y aristotélicos de su filosofía. Por otro lado, en el campo de las matemáticas, es el padre de la geometría analítica y en el campo de la física, es el padre del mecanicismo y uno de los primeros expositores del principio de inercia. En el pensamiento de Descartes hay además una ruptura aunque no de forma completa con la escolástica de su tiempo. Ahora bien, parecería que desde el campo de la experimentación científica Descartes se quedó limitado, ya que creía que antes de conocer el universo se debía de conocer las figuras geométricas que serían las herramientas para llegar a la naturaleza. Pareciera ser también que su gusto por las matemáticas lo hizo inclinarse más por el racionalismo idealista que por el empirismo y de ahí que la razón fuera el fundamento de todo su sistema. En ese sentido, Descartes no pudo desligarse de la fascinación 
por las ideas innatas y por la intuición intelectual. Evidentemente, el racionalismo sería la contraparte del empirismo desarrollado por filósofos posteriores. En fin, Descartes indefectiblemente valoró más la razón que los sentidos, pero era una razón que, de ningún modo, estaba peleada con el dogma cristiano de un Dios, fundamento ontológico de todo lo existente. En un próximo artículo se discutirán las últimas cuatro conferencias que cerraron este importante ciclo de conferencias cartesianas.

\section{Referencias}

- Bajo el signo de Descartes: La conferencia del Rector Navarrete. (13 de septiembre de 1937). Diario Nuevo, p. 1.

- Brillante acto universitario. (14 de septiembre de 1937). Diario Nuevo, p. 2.

- Cassius Jackson Keyser y el tricentenario de Descartes, (28 de julio de 1937). Diario Nuevo, p. 3.

- Claros, R. F. (1937). La teoría cartesiana de las verdades eternas. La Universidad, Órgano de la Universidad Autónoma de El Salvador, 2: 137-156.

- Como juzga la prensa la labor cultural del General Martínez. (20 de septiembre de 1937). Diario Oficial, Suplemento La República, p. 4.

- Díaz Samayoa, V. (21 de septiembre de 1937). Descartes, panorama biográfico I. Diario Oficial, Suplemento La República, p. 3.

- Flores, S. (1937). Del origen y de la perennidad de la filosofía. La Universidad, Órgano de la Universidad Autónoma de El Salvador, 2: 89-118.

- Heriberto. (1937). Descartes ante la razón y la fe. La Universidad, Órgano de la Universidad Autónoma de El Salvador, 2: 65-88.

- Hernández, F. A. (6 de febrero de 1932). La Universidad y El Ejército. El Día, p. 2.

- Jovel, E. (1937). La obra matemática de Renato Descartes. La Universidad, Órgano de la Universidad Autónoma de El Salvador, 2: 119-136.

- Lara-Martínez, R. (2011). Política de la Cultura del martinato. San Salvador: Editorial Don Bosco.

- Llerena, J. (9 de septiembre de 1937). El homenaje a Descartes. Diario Nuevo, pp. 1-2. 
- Morán, F. (21 de septiembre de 1937). Bajo el signo de la democracia. El Diario de hoy, p. 8.

- Navarrete, S. (1937). Bajo el signo de Descartes. La Universidad, Órgano de la Universidad Autónoma de El Salvador, 2: 9-38.

- Ochoa, A. R. (23 de septiembre de 1937). Sugerencias a fin de que se radiodifundan las conferencias que se dictan en la Universidad. Diario Nuevo, p. 5.

- Opiniones sobre Descartes publicadas en París. (20 de septiembre de 1937). Diario Oficial, Suplemento La República, p. 2.

- Reformas Universitarias. (11 de febrero de 1932). El Día, p. 4.

- Reformas Universitarias V. (19 de febrero de 1932). El Día, p. 4.

- Salvatierra, S. (1937). Sobre la formación de nuestra propia cultura a la luz de Descartes. La Universidad, Órgano de la Universidad Autónoma de El Salvador, 2: 39-64.

\section{Notas}

1 A propósito de la organización de este ciclo, el Diario Oficial, Suplemento La República, publicó la primera entrega de una biografía de Descartes escrita por Vicente Díaz Samayoa en la cual este estableció que Descartes procedía de una familia francesa noble y acaudalada de Touraine y que Descartes se había educado entre costumbres refinadas y pulcras. Luego estudió con los jesuitas donde recibió una educación humanista y teológica, aprendió latín, lengua obligatoria en ese tiempo; pero como ensayista prefirió utilizar el francés a tal grado que ha sido reputado "como uno de los fundadores de la prosa clásica francesa". Se cree que Descartes inició su vocación filosófica a los 14 años cuando empieza a cuestionar los argumentos pontificales de sus maestros" (Díaz Samayoa, 1937, p. 4).

2 Cuando se estaba dando todo este movimiento de celebración de los 300 años de publicación del Discurso del Método en El Salvador, en París
(Francia), aparecieron publicadas una serie de opiniones sobre Descartes, entre ellas destacaba la del historiador italiano Gulielmo Ferrero quien estableció: "No hay duda alguna que la crisis política que comenzó en el mundo occidental con la Revolución Francesa, fue un efecto de los progresos del racionalismo. A medida que el hombre se habituó a razonar, se mostró cada vez más opuesto a los gobiernos basados en el principio hereditario. La filosofía de Descartes fue una de las causas de la Revolución Francesa". (Opiniones sobre Descartes publicadas en París, 1937, p. 2).

3 Sofonías Salvatierra (1882-1964), fue uno de los más importantes historiadores centroamericanos del siglo XX, como intelectual apoyó el unionismo de Salvador Mendieta y además fue un miembro destacado de la masonería nicaragüense. Desde el punto de vista político-social apoyó el obrerismo. Algunas de sus obras fueron: Ideales 
y esperanzas (1914), La evolución de la doctrina liberal (1916), Los partidos politicos y la patria (1918), Azul y Blanco (1919), Comentarios (1941), Ideologias (1946) y Hechos e ideas (1948) entre otros.

4 En el campo meramente científico, Descartes, también fue muy cuestionado. Explayó su cosmología en su obra Le Monde, la cual sirvió para coordinar todo lo que se sabía sobre la naturaleza esencial de las cosas en ese momento, pero tenía como defecto que estaba ausente del concepto de masa, por lo que tuvo que ser rechazada. Por otro lado, los teoremas científicos de Descartes fueron muy interesantes, pero por sus múltiples errores fueron sustituidos por los de Huygens y Newton, (Barry). Por otro lado, Machel Foster negó que Descartes hubiese sido fisiólogo, aunque autores como William pensaban que Descartes realizó una serie de postulados que constituirían el fundamento de la fisiología moderna. (Cassius Jackson Keyser y el tricentenario de Descartes, 1937, p. 3). 